are considered to play some part in the increase of their frost hardiness.

Institute of Low Temperature Science,

AkIra SakaI

Hakkaido University,

Sapporo, Japan.

I Sakai, A., Low Temp. Res., Ser. B, 17, 29 (1959).

${ }^{2}$ Sakai, A., Nature, 185, 698 (1960).

${ }^{3}$ Sakai, A., Low Temp. Res., Ser. B, 18, 24 (1960).

- Salt, R. W., Canad. J. Zool., 37, 59 (1957).

${ }^{5}$ Salt, R. W., Canad. Entomologist, 89, 491 (1957).

\section{Growth of Lake Victoria Phytoplankton in Enriched Cultures}

IT has been stated that many of the natural waters of Africa are short of sulphates ${ }^{1}$, and as a broad generalization this is not to be denied. However, it has also been suggested that sulphates, as well as nitrates and phosphates, are a limiting factor for plankton growth in Lake Victoria ${ }^{2}$, and that shortag $\theta$ of sulphates in solution is a factor affecting the productivity of the Lake ${ }^{3}$. During a recent sixmonths stay at the East African Fisheries Research Organization Laboratory in Jinja, Uganda, a small part of my time was devoted to culture experiments, and some successful attempts were made to grow Lake Victoria phytoplankton in laboratory culture.

The phytoplankton most usually dominant in Lake Victoria is Melosira nyassensis var. victoriae, though other diatoms, including $M$. granulata, $M$. italica, M. agassizii and Nitzschia acicularis, and blue-green algae, including Aphanocapsa elachista, Merismopaedia elegans and Lyngbya circumcreta, are often present. Melosira is the most important genus and forms the major source of food, in the Lake itself, for the herbivorous fish, Tilapia esculenta and $T$. variabilis, and most attention was paid to Melosira in this investigation.

To each of thirteen clean, sterilized, plugged $250-\mathrm{ml}$. conical flasks was added a $125 \mathrm{-ml}$. aliquot from a fresh, well-mixed, water sample from the Lake. One of these was treated as a control, and to each of the others was added sterile nutrient solution as follows : to cultures $S_{1}, S_{2}$ and $S_{3}, 10 \mathrm{ml}$. of magnesium sulphate solutions of such concentrations as to produce culture concentrations of, respectively, $1 \cdot 3,13$ and $130 \mathrm{mgm} . / \mathrm{l}$. of sulphate ; to cultures $P_{1}, P_{2}$ and $P_{3}$, $10 \mathrm{ml}$. of dipotassium hydrogen phosphate solutions to produce, respectively, $0 \cdot 874,8 \cdot 74$ and $87 \cdot 4 \mathrm{mgm}$./l. of phosphate ; to cultures $N_{1}, N_{2}$ and $N_{3}, 10 \mathrm{ml}$. of potassium nitrate solutions to produce, respectively, $1.07,10.7$ and $107 \mathrm{mgm}$./l. of nitrate. To each of a fourth series of three cultures, $S P N_{1}, S P N_{2}$ and $S P N_{3}$, was added a mixture of the three nutrient substances at the concentration-levels as described. In calculating these concentrations it was assumed that sulphate, nitrate and phosphate were nil in the Lake water.

Counts of algae were made, by the sedimentation method $^{4-8}$ in the original Lake sample, and for each of the thirteen cultures at intervals of six or seven days for the next three weeks. A final count was made for some of the cultures after a further four weeks.

The response of Melosira (mainly $M$. myassensis var. victoriae) to some of these different cultures is shown in Fig. 1. No growth occurred in $S_{1}$ and $S_{2}$, and the difference between $S_{3}$ and the initial inoculation density is insignificant. It can be stated, therefore, that added sulphate had no effect on the growth of Melosira. Nitrate at 1.07 and $107 \mathrm{mgm} . / 1$. had no effect on the growth of Melosira, and the cultures $\dot{N}_{1}$ and $N_{3}$ are not recorded in Fig. 1. Nitrate at $10.7 \mathrm{mgm}$./ . (culture $N_{2}$ ) apparently boosted growth initially but after a further six days many dead cells were found in the $N_{2}$ culture. On the other hand, the addition of phosphate, particularly in the most dilute form, resulted in a significant increase in Melosira. After a further four weeks there were more than 3,000 cells per $\mathrm{ml}$. in culture $P_{1}$. Melosira also showed a significant increase in culture $S P N_{3}$, where all three nutrients were added at the most concentrated level. No growth occurred in $S P N_{1}$ or $S P N_{2}$; but the reason for this is unknown.

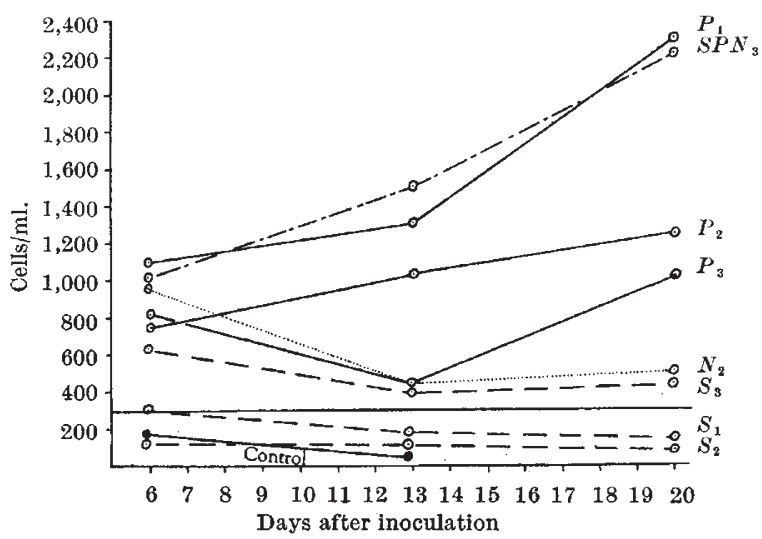

Fig. 1. Effects of added nutrients on growth of Melosira spp. in mixed cultures. Horizontal line, original inoculation density

None of the three species of blue-green algae investigated showed a significant increase on the addition of phosphate, nitrate or sulphate; but factors other than nutrient limitations might have been responsible for this.

The Chlorococcales present in the original inoculum, especially Ankistrodesmus falcatus, showed an increase in all the cultures with additional nutrients, least so for phosphate and most for nitrate at $107 \mathrm{mgm}$./l. For these forms, then, the level of sulphate concentration in Lake Victoria might be, with nitrate and phosphate, a limiting factor, and this agrees with the results of culture experiments in which test algae were used $^{2}$.

The most important genus, Melosira, in the Lake Victoria phytoplankton, however, is apparently not limited by the level of sulphate but is sensitive to phosphate, and hence the biological productivity of Lake Victoria, at the present time, is probably more dependent on phosphate than on sulphate.

I should like to express my gratitude to the Colonial Office for the award of a six-months research fellowship during the tenure of which this work was carried out.

Botany Department,

John H. Evans

Royal Holloway College

(University of London),

Englefield Green, Surrey.

1 Beauchamp, R. S. A., Nature, 171, 769 (1953)

${ }^{2}$ Fish, G. R., E. Afric. Agric, J., 21 (1956).

${ }^{3}$ Beauchamp, R. S. A., Nature, 181, 1634 (1958).

- Utermohl, H., Verh. int. Ver. Limnol., 5, 567 (1931).

${ }^{5}$ Lund, J. W. G., J. Ecol., 37, 389 (1949).

' Lund, J. W. G., Kipling, C., and Cren, E. D. Le, Hydrobiol., 11, 143 (1958). 